\title{
Quench Propagation and Detection in the Superconducting Bus-bars of the ATLAS Magnets
}

\author{
A.V. Dudarev', A.V. Gavrilin', H. ten Kate', E. Sbrissa', \\ A. Yamamoto ${ }^{2}$ D. F. Baynham ${ }^{3}$, M. J. D. Courthold ${ }^{3}$, and C. Lesmond ${ }^{4}$ \\ 'CERN, Geneva 23, CH-1211, Switzerland, ${ }^{2} \mathrm{KEK}, \mathrm{l}-1$ Oho, 'l'sukuba, Ibaraki 305, Japan, \\ ${ }^{3}$ Rutherlord Appleton Laboratory, OX-11 OQX, UK, ${ }^{4}$ CEA/Saclay, DSM/DAPNIA/STCM, F-91191, France
}

\begin{abstract}
The ATLAS superconductiny magnet system comprising Barrel (BT) and End-Cap Toroids (ECT) and also Central Solenoid (CS) will store more than 1.5 (JJ of magnetic energy. The magnet system will have many superconducting buslyars, a fow meters long eacl, running from tle current leats to Central Solenoid and loroids as well as between the coils of each Toroid. Quencle development in the busbars, i.e., the normal zone propagation process along the lyushar supereonductors, is slow and exhibits very low voltages. Therefore, its timely and appropriate deteclion represents a real challenge. The temperature evolution in the husbars under quench is of primary importance. Conservative caleulations of the temperature were performed for all the ragnets. Also, a simple and effective nethod to detect a normal zono in a bushar is presented. $A$ thin superconducting wire, which normal resistance can be easily detected, is placed in a good thermal contact to busbar. Thus, the wire can operate as a straightforward and low-nnise quench-rletcetor.
\end{abstract}

\section{INTRODUCTION}

In the large superconducting thagnet system of the ATLAS detector [1], the stored encrgy will be dissipated inside the coils in the case of a quench event. Special quench heaters embedded into each coil initiate multiple normal zones to spread the heat and therewith to prevent coil overheating and to miminise thermal shock effects $[2,3,4]$. In particular, in the case of heater failure, the normal zone behavior in the superconducting busbars, routing inside the cryostats, is important for the quench protection of the wholc magnet system. For instance, such supcreonductimg busbars connect all the Toroid coils in series.

At the rated cutrent, the normalization time for one coll is less than ten seconds. The time required to discharge fast the whole magnet system is estimated to be about one minute. The quench-back effect due to eddy currents in the coil casings produccs normal zones in initially non-quenched coils within $25-35 \mathrm{~s}$, When a normal zone propagates along the busbar within a few seconds, it will help to dissipate the stored enorgy more uniformly. In such a case, there is no problem if a quench occurs in the busbar conductor.

However, the busbars will be arranged mainly within a low magnetic field region where the normal zone propagation velocity is correspondingly loo. Electrical joints are usually good heat sinks atid can also impede or even stop the normal zone propagation. Then, in the case of a quench of the busbar, there is the danger to overheat the conductor, and

Manuscritht received September 26, 1999

A.V. Dutlacev e-mail: Alexey.Didarev@eem.ch
TABLE I

PARAMETERS OF THIE ATLAS CONDUCTORS

\begin{tabular}{|c|c|c|c|}
\hline Conductor & $\mathrm{CS}$ & $\mathrm{BT}$ & FCT \\
\hline Widlh (mm) & 30 & 57 & 41 \\
\hline 'Thickness (inin) & 4.25 & 12 & 12 \\
\hline Openting cument (kN) & 7.6 & 20 & 20 \\
\hline RRR at I $\mathrm{T} \& 4.5 \mathrm{~K}$ & 250 & 400 & 400 \\
\hline Stabjliser arca (mm $\left.{ }^{2}\right)$ & 110 & 630 & 430 \\
\hline
\end{tabular}

hence a sensitive quench detection system is noeded.

During magnet energizing at low current, a nomat zone can be spatially limited or propagate very slowly. In this case, if a normal zone appears, voltage measurements on the busbar will only enable a quench ovent to be detected with some delay when the conductor is already al a high temperature.

\section{BISSEARS AND QUENCH PROPAGATION}

The same conductors are proposed to be used both for the windings of the magnet coils and for the bustars. Ail the coils will be wound from a Cu/NbTi Rutherford type compositc superconducting cable co-cxtruded in a thick aluminium stabilizer. The main parameters of the ATLAS conductors are given in Table I.

The ATL $\Lambda$ S magnet coils wi]t be cooled indirectly [1]. A proposed layout of the chancteristic superconducting busbars is shown in Fig. 1, $\Lambda$ conductor is placed into special thick alumiuium housing. It is also surrounded with ground insulation, which thickness is about 1-1.5 mm. The layout (a) corresponds to the Central Solenotd and Barrel Toroid busbars, One (for BT) or two conductors (for $C S$ ) will be used as conducting path. A liquid helium tube is attached to the housing that provides necessary cooling conditions. The layout (b) is typical for the ECT where the busbar housing is attached to the cold mass of the ECT coil. Its cooling is provided by thermal conductivity.

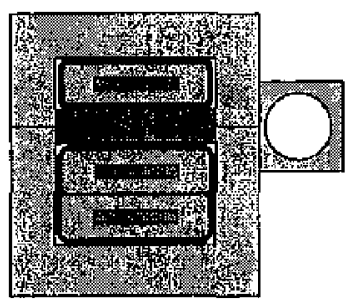

a)

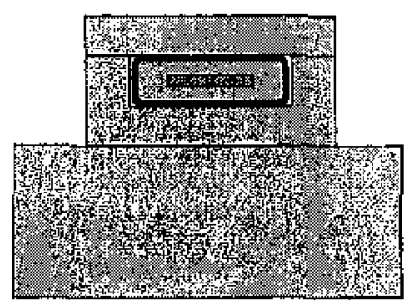

b)
Fig.1 Proposcd layouts of busbars. 


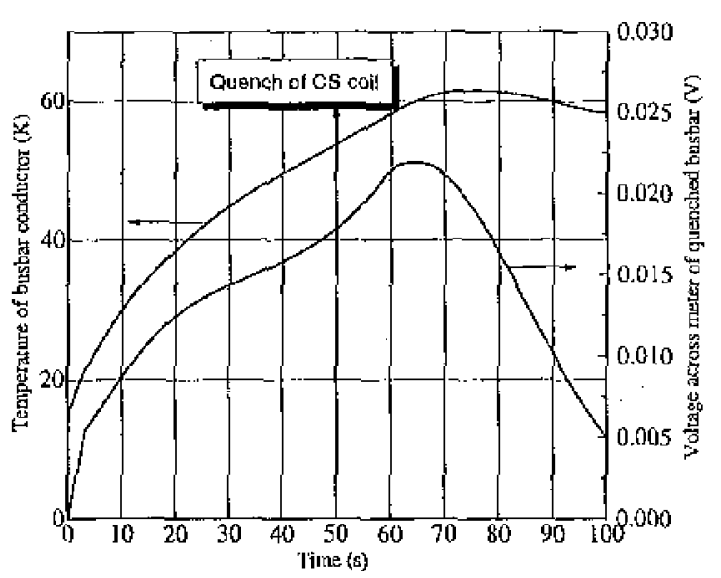

Fig. 2 Miximm temperathre and voltage drop across one meter of the quenched busbar of the Centml Solenoid ( $50 \mathrm{~s}$ delay in the coil quench).

\section{A. Central Solenoid}

The Central Solenoid has a $10-\mathrm{m}$ long chimney between the coil and the current lead box. The superconducting busbat made of two parallel conductors is inside [4]. This busbar passes through the Barrel Toroid region where the spaceaveraged walue of the magnetic ficld is about $1 \mathrm{~T}$ at the first four meters of the busbar. The additional parts of the CS busbar are in a region with low magnetic field. The Central Solenoid will be charged by an independent power supply. We assume in our calculations that the conductors are well glued to the aluminum housing.

A computer-simulated behavior of the busbar under quench is shown in Fig.2 demonstrating the busbar temperature and voltage. If the normal zone does not propagate through the low magnelic field region due to the good cooling conditions in the very beginning of the quench cvent, the power dissipation in the aluminum housing will block the helium flow in the cooling tubes within a few seconds. The cooling conditions in this case become quasin. adiabatic and the normal zone propagates with the velocity of more than $0.5 \mathrm{~m} / \mathrm{s}$. Since the joint region is rather short (about $0.5 \mathrm{~m}$ ), two seconds are enough to normalize the joint. But even in the very pessimistic case, where a quench of the Central Solenoid will start at fifty seconds after the busbar quenches, the maximum calculated temperature of the busbar is less than $70 \mathrm{~K}$.

\section{B. Barrel Toroid}

The same approach as for the CS busbar can be used for the analysis of processes in the Barrel Toroid busbar. Eight BT coils placed in separated cryostats are connected by a cryogenic ring [2]. In each section of the cryogenic ring, the length of the busbar incluive joints is about $5 \mathrm{~m}$. The average value of the magnetic field at the BT busbar region is about $1 \mathrm{~T}$. The thickness of the ground insulation is planned to be $1.5 \mathrm{~mm}$. Each joint can be considered as a double conductor. Under adiabatic conditions, starting as a result of helium stopping in a few of seconds after the quench

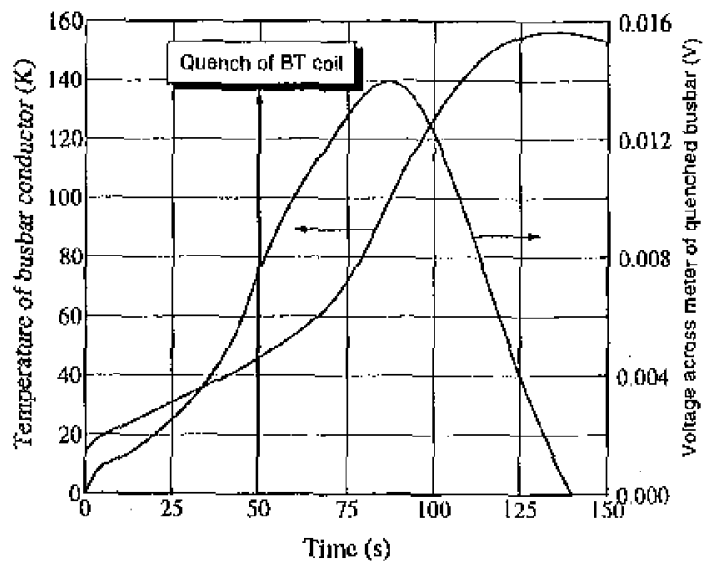

Fig 3 Maximum temperature and voltage drop across one meter of the quenelind busbar of the Barrel Toroid ( $50 \mathrm{~s}$ delay in the coil guench).

initiation, the normal zone will propagate through the joint within three to four seconds. For the doubled conductor in the busbar housing the normal zone propagation velocity is bigher than $0.3 \mathrm{~m} / \mathrm{s}$ under adiabatic conditions. The temperature and voltage drop versus time is shown in Fig. 3 . It is estimated that the maximum temperature is less than $160 \mathrm{~K}$ when the BT fast discharge starts with $50 \mathrm{~s}$ clelay after the busbar has quenched.

\section{End-Cap Toroid}

Each of the two End-Cap Toroids will consist of eight svils placed in a cryostat [3]. The coils will be electrically connected in series, using superconducting busbars. The length of busbar between the joints of the coils will be about 1.5 meter. The busbar housing will be anchored to the surface of the cold mass. After initiation, a normal zone propagates within seconds under quasi-adiabatic conditions. If the joint is made in the "praying hands" shape, one can assume that the propagation across the joint is rather fast. Similat results as for the CS and BT busbars are numerically obtained and

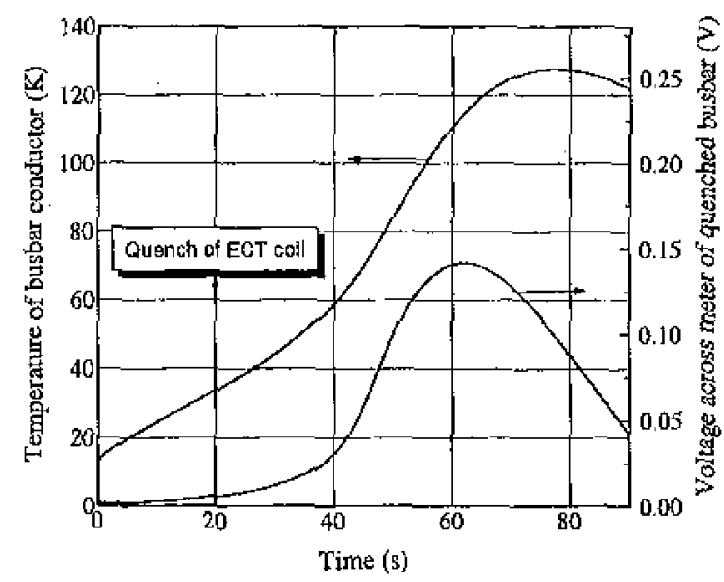

Fig. 4 Maximum temporature and yoltage drop across ond meter of the quenched busbar of the End-Cap Toroid (20 s delay in the coil quench). 
shown in Fig.4. The current density in the ECT busbar is about 1.5 time higher than in the BT and CS and warming up is nearly two times faster. A rough analysis gives that a few seconds woltd be sufficient to normalize the whole busbar. However, even when this value is twenty sconds, the maximum temperature does not exceed $140 \mathrm{~K}$ when the magnet system discharge starts with such delay.

\section{Busbar quench and voltage detection}

Even when there are no obvious problems with the ATLAS busbars, the protection system has to be activated as early as possible. The fastest way of quench detection is the voltage drop measurements. However, it is of primary importance to prevent false activation of the protection system due to noise. For the whole magnet with well-know bridge detectors, the voltage threshold is chosen to be $1 \mathrm{~V}$. On the worst assumption, a normal zone does not propagate from the busbars to the coils. In the ATLAS coils at operating current, the busbar voltage rise can be reliably detected after the bus concluctor temperature reaches $75-100 \mathrm{~K}$. For the quench detection of the BT busbars, a switch/voltmeter would require a voltage threshold of $50 \mathrm{mV}$ whicl would controt each of the lifteen bus lines. $A$ quench event at such voltage lovel can be delceted with approximately $40 \mathrm{~s}$ delay. However, the $50 \mathrm{mV}$ delcction level canses serious noise problems and it would be better to introduce a new reliable method,

\section{SUPHRCONDUCTING QUENCH DETECTOR}

\section{A. Introduction}

A simple method of quench detection in the busbars is suggested. The idea is as follows. On the surface of the atuminum housing of the supereonducting busbar an insulated thit superconductor, sec Fig. 5 , is glued. If a busbar quench takes place, the temperature of supercouductor will increase in accordance with the temperature increase of the quenched parts of busbar. When the superconductor temperature becomes equal to the critical temperature, it becomes normally condueting. Through its resistance control, the quench event of the husbar can be detected, of cotrse with some time delay. For the best performance of such a superconducting quench detector (SQD), the following requirements are evident: high electrical resistivity of the superconducting material and a bifilar lay-out in order to

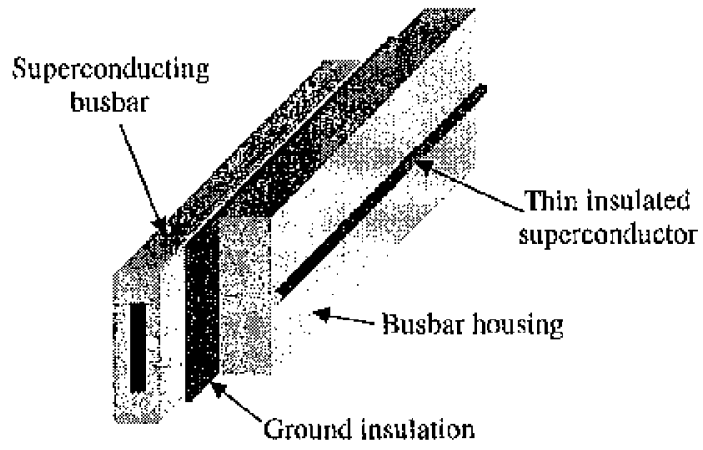

Fig. 5 A sitnple supercondueting quench detector.

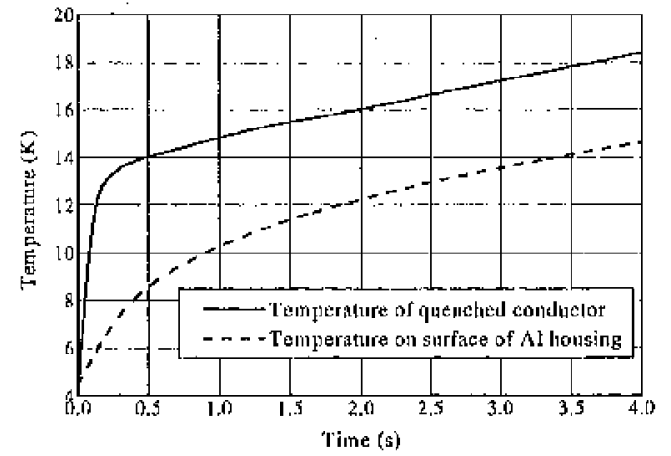

Fig. 6 Temperature tising of the quenched busbar aut its aluminum housing.

avoid noise problems, small thickness of the insulation and small mass of the superconducting clement to reach the fast reaction.

\section{B. Reaction time}

One of the impotlant things regarding any quench detcetor is the reaction time. For our SQD, the raction time is determined by the heat transfer conditions between the quenched part and the detector element. Assuming that the dimensions of SQD are much less than the busbar dimensions the characteristic time scale of the $\$ Q D$ warming up is dependent on thickness, heat capacity and heat conductivity of the SQD conductor and its insulation. We have found that the typical reaction time of the detector does not exceed $0.1 \mathrm{~s}$. If the $\mathrm{SQD}$ is placed as shown in Fig.5, it is necossary to calculate the temperature cvolution of the busbar housing surface. The rcsult of 2-D calculations, taking into account a current diffusion into the alumintm stabitizer and transient hoal processes, is given in Fig. 6. The busbar housing is $15 \mathrm{~mm}$ thick and made from alumimun alloy. A sale $1.5 \mathrm{~mm}$ ground insulation is the main barrier for the heat conduction to SQD. Nevertheless, the temperature of the housing surface turns out to be at $10 \mathrm{~K}$ in one second. Therefore, the SQD enables easy and reliable detection of a normal zone within two seconds. Thus, the reaction time of the SQD on quench of the busbar is much shorter than the expected reaction time of the switch voltmeter arrangement.

\section{Material and sensitivity}

The most suitable material for the superconducting quench detector seems to be Nbli alloy that has high enough resistivity, As obvious, it has also the same critical
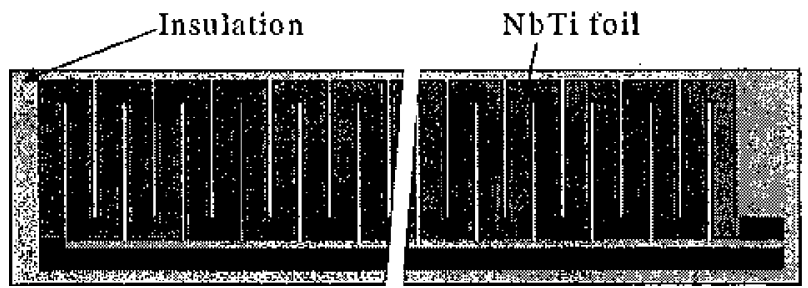

Fig. 7 Sketch of the foil snperconducting quench fletector (SQD). 


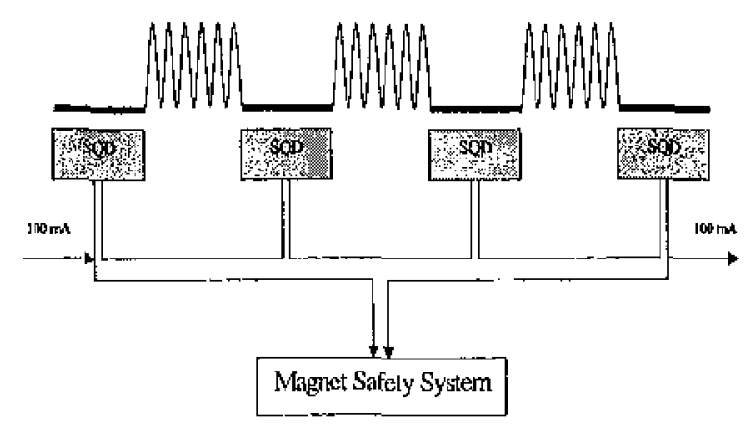

Fig. 8 A one-channel scheme for quench detection it all the busbars.

temperature as the superconductors from which the busbars are made. Thus, if a quench occurs in the region with a bigh magnetic field the reaction time will be correspondingly shorter than in a low ficld region. A NbTi foil can be chosen as the sensitive element of SQD. A pattern sketch of the foil SQD is shown in Fig.7. The linear resistance of the detector is expected to be about $100 \mathrm{Ohm} / \mathrm{m}$. With a typical measuring current of $100 \mathrm{~mA}$, the output signat will be high cnough to be detected without any problem. In fact, the SQD behaves as a voltage amplifier enabling 10 detect reliably and noise frec quenching busbars. Another simple SQD can be made of a thin $\mathrm{NbTi/CuNi-matrix} \mathrm{superconducting} \mathrm{wire} \mathrm{typically} \mathrm{used}$ in AC applications. Such a twisted bifilar pair of thin insulated superconductors is tree of any noise problems and attractive due to the very low cost.

From the point of view of the reaction tinc, the distance between the quenched conductor and the SQD should be as shorl as possible. It can be more easily realised along the connections between the coils and on the joints of the double pancakes in each coil. The exact position of the SQD should be discussed with the coil manufacturer.

\section{Electrical Circuit}

The simplest way to form the quench detection scheme for the entire Toroid is to connect all the individual SQD on the busbars in series. In this case, one channel is sufficient for quench coutrol which makes the detection system very reliable, see Fig.8. Redundancy in the SQD system can be easily implemented. If connections between the eloments are placed inside the cryostat where the resistance of the measurement wires is negligible, the SQD is the simplest logical element with "Yes/No-Quench" reaction. There are no special requirements for the conjecting wite. If necessary, cach element can be controlled to determino the location of the normal zone origination.

\section{CONCLUSIONS}

In the case of a quench event, the ATLAS magnet system superconducting busbars are not expected to warm up higher than $200 \mathrm{~K}$ oven with very slow normal zone propagation in the busbars.

$\Lambda$ nomal zone in a quenched superconducting busbar can be detected through direct voliage measurements or with a superconducting quench detector ( $\mathrm{SQD}$ ) as suggested here. We plan to develop and test various types of superconducting quench detectors on model coils to check their reliability for application in the ATLAS magnet system.

\section{REFERENCES}

11] ATLAS Magnet System, TDR, CERN/LHCC/97-18, 1997

[2] ATLAS Hartel Toroid, TDR, CLRN/LHCC/97-18, 1997

[3] ATLAS End-Cap Toroid, ['DR, CERN/LHCC/97-20, 1997

[4] ATLAS Central Solenoid, TDR, CERN/I.HCC/97-21, 1997 